\title{
TRADUZIR, REMONTAR: ANTOLOGIA E A INVENÇÃO DO OBJETO TRADUZIDO
}

\author{
Mauricio Mendonça Cardozo 1 \\ ㄴUniversidade Federal do Paraná, Curitiba, Paraná, Brasil
}

\begin{abstract}
Resumo: Este ensaio tem por objetivo discutir os diferentes sentidos da noção de traduzir como remontar, explorando as acepções desse verbo em português, seja no sentido da (re)montagem (em sua acepção como técnica cinematográfica), seja no sentido da referência a uma origem. À luz dessa reflexão preliminar, este ensaio faz uma breve reflexão sobre as relações entre tradução e antologia, encerrando-se com uma leitura crítica do projeto de tradução da poesia de Bertolt Brecht, publicada por André Vallias em 2019.
\end{abstract}

Palavras-Chave: Tradução de Poesia; Traduzir como remontar; Tradução e Antologia; Poesia de Brecht; André Vallias

\section{ON THE DIFFERENT MEANINGS OF TRANSLATING AS "REMONTAR": ANTHOLOGY AND THE INVENTION OF THE TRANSLATED OBJECT}

\begin{abstract}
This essay aims at discussing the different meanings of the notion of translating as "remontar", exploring the semantic field of this verb in Portuguese, whether in the sense of "montage" and "(re)montage" (in the sense of the film editing technique), or in the sense of referring to an origin. In the light of this preliminary reflection, this essay briefly discusses the relations between translation and anthology, to end up with a critical reading of the translation project of Bertolt Brecht's poetry, published by André Vallias in 2019.
\end{abstract}

Keywords: Poetry Translation; Translating as remontar; Translation and Anthology; Brecht's Poetry; André Vallias 


\section{NÃO SE DIZ voltar um rio se vai com espirais de alga se devolvendo \\ não se diz ficar quando ascende pela onda ao espírito do movimento nunca as mesmas águas mas por revide sempre remontando sua fonte Marcos Siscar ${ }^{1}$}

Nas curvas desse rio que serpenteia o poema "Não se diz", de Marcos Siscar, nas águas heraclitianas desse rio que não cessa de se ir, desse rio que se vai e a que se vai sem volta, não se diz remontar sem desembocar (n)a equivocidade desse verbo caudaloso. Nesse rio corrente, da vida e da poesia, as águas nunca as mesmas, reagindo a sua condição incessantemente fluvial, sempre remontam sua fonte, o que significa dizer, para explorar aqui apenas algumas das nuances que o verbo remontar reverbera em sua expressão transitiva direta, que essas águas sempre recompõem, tornam a montar, montam de novo sua fonte; mas também significa dizer que essas águas elevam sua fonte, ascendendo "ao espírito do movimento" - no sentido de um ascender conforme, à medida (d)esse espírito semovente, mas também no sentido de um ascender $a$ essa semovência, como se essa condição se desenhasse com o estatuto de um lugar, de um destino.

$\mathrm{O}$ uso assertivo do verbo remontar em sua transitividade direta, especialmente num sintagma que tem o substantivo fonte por objeto, produz um discreto tensionamento da opção por tal regime verbal, matizando esse uso com uma nota provocativa; e o faz justamente porque esse sintagma (remontar + fonte) parece não conseguir deixar de evocar a expectativa (não consolidada) do uso (talvez mais corrente) desse verbo em sua transitividade indireta, como em "remontar às fontes". Em outras palavras, na condição dessa opção potencialmente provocativa de transitividade - que não diz a outra transitividade possível, embora não deixe de evocá-la -, as águas desse rio-poema, no mesmo movimento em que dizem re-

${ }^{1}$ Siscar, Metade da arte, 85, grifo meu. 
montar sua fonte no sentido (transitivo direto) da remontagem e da elevação (e justamente porque o dizem), também manifestam um desvio da compreensão mais corrente desse movimento, no sentido (transitivo indireto) da restituição ou remissão à fonte, da volta a um lugar de origem - afinal, "não se diz voltar um rio se vai".

Nesse tensionamento possivelmente provocativo do uso particular do verbo, o verso de Siscar cria um dispositivo simples, mas capaz de dramatizar o modo de dizer remontar, que se diz pelo que diz, mas também pelo que nesse mesmo gesto "não se diz" (pelo que se evoca, mesmo que não se diga). No verso em epígrafe, remontar é dizer que as águas do rio sempre montam de novo, não cessam de reconstruir sua fonte, e como fazê-lo é sempre também um modo de dar de novo à fonte um lugar, uma atenção, talvez esta seja já uma forma de elevação diante de tudo o que corre e passa no caudal contínuo de todas as coisas; e ao deixar de dizer remontar como simples movimento de volta à fonte, mas sem deixar de evocar essa acepção possível, o verso diz (pelo que não se diz) que o modo dito (de remontar a fonte) é também um modo de resistir à expectativa do modo não dito (de remontar à fonte), ainda que sem deixar de conviver com ela.

Tendo em conta que essa tensão entre o (se) dizer e o não (se) dizer se estabelece num poema intitulado "Não se diz", que a força dessa dramatização extrapola o corpo desse poema, ressurgindo em vários outros momentos, especialmente ao longo do ciclo de poemas intitulado "A palavra e a dor”, e que Não se diz é também o título do livro em que esse poema foi publicado (Siscar, Não se diz), ${ }^{2}$ talvez possamos localizar, na força discreta dessa dramatização, um caminho produtivo para a leitura não apenas desse poema, mas também de todo o ciclo de que o poema faz parte. No entanto, para a reflexão que aqui se abre e que só pode se valer da leitura dos versos em epígrafe como ponto de partida, caberá transcender o escopo particular desse dispositivo no contexto da obra de Siscar, tomando-o como uma espécie de figura em torno da qual podemos

${ }^{2}$ Republicado no livro Metade da arte (Siscar). 
esboçar um pensamento que tem outro objeto em vista: a tradução. Em outras palavras, trata-se aqui de pensar a tradução a partir de alguns dos tensionamentos do modo de dizer remontar.

\section{Traduzir: remontar o objeto direto, remontar ao objeto indireto}

A tradução é frequentemente associada à força figurativa do verbo remontar em suas diferentes acepções. Cabe, aqui, revisitar brevemente algumas reflexões em que isso ocorre, com especial atenção ao modo como o uso particular desse verbo (e também de sua forma nominalizada, como remontagem) contribui para o desenho da concepção de tradução desenvolvida em cada um desses contextos.

No artigo "Aspectos sociolinguísticos da tradução", ${ }^{3}$ considerando a relação entre o que o autor chama de contexto (marcadores linguísticos) e co-texto (marcadores mais amplos do discurso) ${ }^{4}$ como decisiva para a construção de uma percepção do texto a ser produzido, Fernando Tarallo se vale das noções de montagem, desmontagem e remontagem para nomear as operações constitutivas do processo tradutório:

No momento do transporte de um sistema linguístico para
outro, este entendimento da PROdução do texto é anali-
sado através da PERcepção do tradutor, a fim de que a
MONtagem e DESmontagem do texto da língua de partida
acarretem uma REmontagem fiel na língua de chegada, tal

\footnotetext{
${ }^{3}$ Publicado originalmente em 1984: Tarallo, Fernando. “Aspectos Sociolinguísticos da Tradução”. Tradução \& Comunicação. 4, (1984): 91-106.

${ }^{4}$ Como afirma o autor: "Ao se estudarem variantes linguísticas a partir do desempenho linguístico, a significação de cada uma delas é tomada com base em elementos contextuais e co-textuais. Entre os primeiros, os elementos contextuais, entenda-se o encaixamento da variante dentro do próprio sistema gramatical; os elementos co-textuais enquadram, por outro lado, a variante em um processo maior, mais amplo do discurso" (Tarallo 44).
} 
qual pretende a teoria da tradução das equivalências, das probabilidades. (Tarallo 44, grifos do autor)

A remontagem surge, na reflexão de Tarallo, como uma das operações de um processo tradutório descrito como "transporte de um sistema linguístico para outro": trata-se de um remontar no sentido de "montar (algo) de novo", mas dado que esse procedimento é ditado pelas operações preliminares de montagem e desmontagem do texto original, podemos dizer que, para o autor, essa operação de remontagem (re-construção) de um texto (como texto traduzido) cumpre o propósito de reproduzir os mesmos princípios de montagem do texto original. A tradução seria, portanto, ditada pelas leis da equivalência - ainda que por uma "equivalência com base em variação" (Tarallo 34), por uma "equivalência de registros linguísticos" (Tarallo 36) - e por um princípio de fidelidade - que o autor associa à exigência de uma perda mínima de informação e de carga semântica do texto original. Em outras palavras: para Tarallo, que tem em vista a tradução em geral (não uma modalidade específica, como a da tradução literária) e organiza seu olhar com uma sensibilidade sociolinguística para o objeto em questão, o processo tradutório consistiria em remontar (construir como remontagem) o texto traduzido para fazê-lo remontar (fazer equivaler) ao original.

Já ao pensar a tradução no contexto mais amplo de uma reflexão sobre a crítica literária, com especial interesse pelas diferentes formas de manifestação crítica na obra de escritores-críticos, Leyla Perrone-Moisés afirma, na introdução de seu Altas literaturas:

Escolhendo sua própria tradição, esses escritores propõem novos cânones. Dialogando com os autores do passado ou do presente, praticam formas particulares de intertextualidade. Exercendo a tradução, arrancam essa prática da condição ancilar a que fora relegada pela metafísica da Obra, para promove-la à categoria de recriação, trabalho em comum e (o que aqui nos interessa) forma privilegiada de crítica: a tradução é, primeiramente, consequência de uma escol- 
ha significativa; e, em seguida, trabalho compreensivo e seletivo de desmontagem e remontagem do texto original. (Perrone-Moisés 14, grifo meu)

Ainda que, para a autora, não se trate de discutir mais centralmente as especificidades do processo tradutório propriamente dito, a tradução surge, no contexto dessa reflexão desenvolvida entre 1980 e 1998, como uma "forma privilegiada de crítica": seja pela natureza crítica do próprio gesto de escolha da obra a ser traduzida, seja por quanto o trabalho compreensivo e seletivo de desmontagem e remontagem do texto original se configura como uma atividade de ordem crítica, à semelhança do que também afirmam, em seus próprios termos, autores como, por exemplo, Haroldo de Campos ("Da tradução como criação e como crítica") e Antoine Berman.

Ou seja, para Perrone-Moisés, que tem em vista exclusivamente a tradução de obras literárias, a tradução, como trabalho de "desmontagem e remontagem do texto original", também consistiria em remontar (construir como remontagem) o texto (traduzido) para fazê-lo remontar ao original. No entanto, ao se afastar da ideia de tradução como transporte entre sistemas linguísticos para se aproximar da ideia de tradução como "recriação" - fazendo reverberar aqui, implicitamente, uma referência ao pensamento poético-tradutório de Haroldo de Campos, de que tratarei em seguida - , a autora caracteriza esse fazer tradutório como uma prática que, para dizer o mínimo, não se limita a "fazer equivaler". Isso porque o trabalho de tradução literária, no entendimento da autora, pressuporia uma compreensão (particular e particularizante) do texto original como um objeto literário (não apenas como objeto textual), ao que corresponde, consequentemente, a identificação, a seleção e a hierarquização dos diferentes aspectos desse texto (como obra literária), que impactarão mais centralmente na operação de tradução como remontagem - e é nisso, exatamente, que consistiria a natureza e o valor crítico dessa operação.

Haroldo de Campos, por sua vez, faz uso do verbo remontar e das noções de montagem e desmontagem em diversos momentos de 
sua obra, ${ }^{5}$ em geral, para referir-se a operações e/ou processos poético-crítico-tradutórios, fazendo reverberar em seus escritos uma tradição moderna de discussão da noção de montagem em contextos como o das vanguardas do século XX, do cinema (de Eisenstein) e dos estudos sobre o ideograma (de Fenollosa e Pound). Contudo, é provável que a passagem mais lembrada de sua obra a esse respeito - talvez mesmo uma das referências mais citadas (em português) quando se trata de associar a ideia de tradução à remontagem - seja uma passagem de seu famoso ensaio "Da tradução como criação e como crítica", apresentado originalmente em um congresso na $\mathrm{Pa}$ raíba, no ano de 1962, e publicado no ano seguinte. Nesse ensaio, Haroldo de Campos se valerá também da força dos verbos desmontar e remontar para detalhar sua visão de tradução:

A tradução de poesia (ou prosa que a ela equivalha em problematicidade) é antes de tudo uma vivência interior do mundo e da técnica do traduzido. Como que se desmonta e se remonta a máquina da criação, aquela fragílima beleza aparentemente intangível que nos oferece o produto acabado numa língua estranha. E que, no entanto, se revela suscetível de uma vivissecção implacável, que lhe revolve as entranhas, para trazê-la novamente à luz num corpo linguístico diverso. Por isso mesmo a tradução é crítica. (Campos, "Da tradução como criação e como crítica", 43, grifos meus)

Como bem sabemos, não se trata, para o autor, de uma desmontagem e remontagem como operação estritamente linguística; trata-se, antes, de desmontar e remontar o texto em sua condição de poema, de poesia, ou ainda, como ele próprio afirma no referido

${ }^{5}$ De fato, a noção de montagem já está presente no Plano-piloto para poesia concreta (Campos A., Campos H. e Pignatari, 1975), do final da década de 50, e ocorre também em diversos outros textos do autor, como, por exemplo, em "Da razão antropofágica: diálogo e diferença na cultura brasileira” (Campos, 1992b, publicado originalmente em 1981). 
ensaio, em sua condição de "máquina da criação". Cabe destacar que o movimento decisivo, nessa passagem, incide sobretudo no modo de circunscrever o objeto da tradução. De fato, a figura da desmontagem e da (re)montagem da máquina tem uma cunhagem inequivocamente mecânica - e, mais tarde, Haroldo chegará mesmo a associar tal operação a uma física da tradução, em oposição a uma metafísica da tradução, que ele associará ao pensamento benjaminiano. No entanto, essa máquina, para o autor, é um corpo vivo, e é justamente por isso que a operação de desmontagem e remontagem tem de ser entendida muito mais como uma espécie de vivissecção do que como uma operação de desmanche e reconstrução.

Em outras palavras: uma vez que o objeto da tradução passa a ser concebido como um corpo vivo, a máquina da criação não pode ser simplesmente desmontada e remontada no sentido de uma operação de desmembramento e religamento de suas peças, dado que isso colocaria em risco a própria condição desse objeto como forma de vida - como poesia. Para Haroldo, desmontar e remontar seriam, antes, modos de revolver as "entranhas" dessa máquina, modos de vivenciá-la intensamente para fazê-la viver sob a forma de suas continuidades e descontinuidades em outro corpo linguístico. Assim, podemos dizer que, para o autor, remontar (construir como remontagem) o texto (traduzido) é, antes de mais nada, construí-lo (paramorficamente) como um poema, como obra viva em língua portuguesa - e é somente nessa condição (de poema em nossa língua) que esse texto, como texto traduzido, poderá cumprir seu sentido de remontar ao texto original (como poema em outra língua). Daí a caracterização dessa operação poético-tradutória como criação e como crítica; e como sabemos, serão muitos os nomes que Haroldo de Campos dará a essa operação ao longo de sua obra, chamando-a inicialmente de recriação, já neste ensaio de 1962, para depois propor suas inúmeras derivações em torno da noção de transcriação.

Como se pode notar a partir desses breves comentários, Fernando Tarallo (como sociolinguista), Leyla Perrone-Moisés (como teórica e crítica literária) e Haroldo de Campos (como teórico e 
crítico da literatura, mas também como poeta e tradutor literário), por falarem de lugares distintos, manifestam uma diferença de visão também no modo como a noção de remontagem surge em suas reflexões sobre a tradução. Se para Tarallo, que não parece ser indiferente ao lugar de um sujeito tradutor no processo tradutório, ${ }^{6}$ as operações de desmontagem e remontagem são descritas como parte de um processo que é determinado por valores de fidelidade e de equivalência (ao original) e que se apresenta como uma espécie de transporte (e também de recodificação) entre sistemas linguísticos, para Perrone-Moisés e Haroldo de Campos (mais próximos entre si do que de Tarallo, como se poderia mesmo suspeitar), as operações de desmontagem e remontagem são caracterizadas como parte de um processo que é de natureza crítica e da ordem da (re) criação. Nas palavras da teórica e crítica literária, a tradução surge como um "trabalho em comum" - em cuja formulação pode-se ler uma ruptura com a visão hierarquizante que anula tanto o tradutor diante do autor quanto o texto traduzido diante da obra original; e nos termos desenvolvidos posteriormente por Haroldo de Campos (Deus e o Diabo no Fausto de Goethe: marginalia fáustica (leitura do poema acompanhada da transcriação em português das duas cenas finais da segunda parte), 75-76), a tradução surge como "canto paralelo" (plagiotropia) - noção que cabe ser pensada também à luz da extrapolação que Haroldo faz, com Valéry, da própria "ideia da literatura como operação tradutora" (Campos, Haroldo de Campos - Transcriação, 61-63).

À primeira vista, portanto, pensar a tradução a partir da figura do verbo remontar não parece fazer muito mais do que reafirmar a noção de que traduzir é (re)montar um texto, ou seja: construir um texto (o texto traduzido) como remontagem de outro, como texto que remonta a um texto original (ao texto tomado como origem). No entanto, os sentidos dessa síntese figurativa variam em face dos diferentes modos de entender, caracterizar e qualificar a

${ }^{6}$ Vale lembrar que o autor associa o entendimento da produção do texto traduzido a uma "percepção" do tradutor (Tarallo 44).

Cad. Trad., Florianópolis, v. 41, no 3 p. 33-57, set-dez, 2021. 
atividade em que o tradutor "(re)monta um texto": entre outros, como uma operação (pretensa ou idealmente) mecânica (de montar um texto de novo, de unir de novo suas peças), como um trabalho de natureza crítica e/ou como um gesto de (re)criação (nesses dois últimos casos, com toda a força crítica e poiética que as noções de montagem e remontagem ganham, por exemplo, no contexto do teatro, do cinema e das artes de vanguarda do século XX). Assim como também variam os sentidos possíveis dessa síntese à medida que consideramos os diferentes modos de entender, caracterizar e qualificar a condição particular em que o texto traduzido "remonta ao texto original": entre outros, na condição de ser (tão idealmente quanto possível) o próprio texto original em outra língua (não se admitindo, nesse caso, nenhuma forma produtiva de diferença), na condição de ser (necessariamente) um texto diferente (admitindo-se que é apenas nessa condição de diferença que o texto traduzido pode dizer de novo o texto original) e/ou na condição de ser um texto que, fundado na força transformadora de uma relação tradutória, ${ }^{7}$ impõe-se também como um texto outro, como forma de alteridade (admitindo-se que sua condição de diferença, para além de mero efeito estigmatizante da relação com o original - na negatividade de uma suposta condição de inferioridade -, também é constitutiva de uma singularidade do texto traduzido e que, portanto, ao cumprir a tarefa de dizer de novo o texto original, o texto traduzido também tem um dizer e um fazer que lhe são próprios - e é justamente nisso que reside seu valor crítico, poético).

\section{Tradução, edição e antologia: corte, (re)montagem e a invenção do objeto traduzido}

Para além de um entendimento da própria escrita tradutória como operação de (re)montagem, pensar a tradução literária a par-

\footnotetext{
${ }^{7}$ A propósito da noção de tradução como poiesis da relação e suas implicações, cf. Cardozo 2018, 2015, 2012, 2009, entre outros.
}

Cad. Trad., Florianópolis, v. 41, no 3 p. 33-57, set-dez, 2021. 
tir de diferentes acepções do verbo (re)montar - e de sua carga figurativa, mesmo em alguns de seus sentidos denotativos - nos leva a considerar ainda um outro aspecto importante: dado que todo processo de tradução pressupõe a definição prévia de um corpo textual como texto de base, essa definição pode implicar, já de partida, um trabalho de construção e estabelecimento textual que é também da ordem da (re)montagem. É bem verdade que nem sempre essa definição - e o trabalho nela implicado - cabe ao tradutor, assim como também são frequentes as situações em que simplesmente não há muito o que definir em relação ao objeto textual que será tomado como texto de base para a tradução, como, por exemplo, nas situações em que não há mais de uma edição da obra em questão. Este parece ser o caso geral da tradução de prosa de ficção, especialmente (mas não exclusivamente) quando se trata da tradução de obras contemporâneas. No entanto, cabe lembrar aqui, também, da tradução de obras (muitas delas em prosa) que têm uma história mais longa e intrincada de edição e reedição, o que em geral (mas não exclusivamente) acontece com obras publicadas originalmente há mais tempo (anteriores ao século XIX): nesses casos, diante de uma variedade de edições críticas e reedições de determinada obra (ou de variantes de um suposto prototexto), impõe-se a necessidade de uma escolha, da opção por uma ou outra forma de estabelecimento do texto de base (por uma ou outra edição crítica, por exemplo), o que pode ter impacto significativo na constituição da unidade textual a ser traduzida.

Penso, por exemplo, na movimentada história de edição de algumas das obras de Goethe, autor que viveu uma época em que ainda começava a se levantar, na Alemanha, a questão dos direitos autorais e em que ainda imperava amplamente a prática de publicação de edições não apenas não autorizadas pelos autores, mas também significativamente modificadas pelos editores - dado o pressuposto de que a obra pertenceria mais a quem a publicasse do que a quem a tivesse escrito. Tomemos por exemplo o próprio Werther, cuja primeira edição foi publicada em 1774 por um editor da cidade de Leipzig chamado Weygand. Depois de duas reimpres- 
sões corrigidas nesse mesmo ano, Weygand, tomando novamente por base o manuscrito original de Goethe (perdido com o tempo), reeditou a obra em 1775. É também desse ano a primeira edição não autorizada da obra, que a crítica considera ter sido adaptada (leia-se: corrigida) segundo as convenções linguístico-ortográficas de Berlim, onde foi publicada pelo editor Christian F. Himburg como parte de uma edição (igualmente não autorizada) dos escritos de Goethe. Himburg publicou mais duas edições da obra, em 1777 e 1779, multiplicando ainda mais as diferenças em relação à primeira edição de Weygand, de 1774. Em 1782, Goethe retoma seu projeto de revisão do Werther, mas foi justamente a edição de Himburg, de 1779, que o autor tomou por base para fazer inclusões, exclusões e rearranjos, corrigindo muitos dos problemas de impressão, mas mantendo, também, boa parte das variantes do texto impresso por Himburg. O texto resultante desse trabalho de revisão, o chamado manuscrito $H$, serviu de base para a famosa edição de 1787 (considerada a última edição revisada pelo autor), publicada por Göschen, em Leipzig. Entre as várias edições críticas do Werther, a edição organizada por Waltraud Wiethölter, com a colaboração de Christoph Brecht (Goethe), oferece, lado a lado, uma versão do texto que remonta à primeira publicação da obra, de 1774 , e uma versão da última edição revisada pelo autor, de $1787 .^{8}$

Tendo em vista esse histórico de edições da obra e tendo em mãos um aparato crítico como o da referida edição, o tradutor pode se ver diante da situação de ter de optar por uma das variantes, ${ }^{9}$

${ }^{8}$ Para uma síntese mais detalhada da história de publicação/edição do Werther, vide, entre outros, o estudo crítico "Die Leiden des jungen Werthers (erste und zweite Fassung)", disponível na edição crítica da Deutscher Klassiker Verlag, referida acima (com destaque à sessão "Entstehung und Bearbeitung": Goethe, pp.909-925). A este e outros propósitos, $c f$. também o ensaio "Mein werter Herr Werther: à guisa de nota liminar" (Cardozo).

9 A maioria das traduções (não apenas para o português) se vale do critério da “última versão revisada pelo autor" para optar pela edição de 1787, o que representa antes um modo de privilegiar essa edição do que alguma forma de demérito para as demais versões. Em 2006, por exemplo, a editora Hedra republicou uma tradução anônima do século XIX, tendo por justificativa justamente o fato peculiar 
assumindo como texto de base, independentemente de sua escolha, o resultado do trabalho prévio de estabelecimento textual realizado pelos editores (um trabalho muitas vezes complexo e minucioso de construção e recomposição do texto e, nesse sentido, também um trabalho de remontagem). Hipoteticamente falando, no entanto, um determinado tradutor poderia ter suas razões e seus critérios - perfeitamente justificáveis de algum ponto de vista crítico - para tomar essas duas edições como ponto de partida de um outro trabalho: o de estabelecimento de um texto de base próprio, de uma espécie de versão intermédia, que, por sinal, só existiria como texto base no contexto desse projeto particular de tradução, explicitando-se, nesse caso, um trabalho que seria também da ordem da montagem e da remontagem (da construção do objeto que passaria a valer como texto de origem) mesmo antes de iniciado o processo de tradução mais propriamente dito. Casos como este não são assim tão comuns, mas quanto mais recuamos no tempo, mais a questão do estabelecimento do texto se apresenta como relevante, por vezes mesmo como uma exigência, a exemplo do que acontece frequentemente na tradução de textos da Antiguidade (da clássica greco-latina, mas também de outras tradições, como a persa, árabe, chinesa etc.), em que, não raro, os trabalhos de tradução e de estabelecimento de um corpus textual (como obra de origem) acabam se somando, fundindo-se num mesmo trabalho.

Contudo, é no universo da tradução de poesia que esse aspecto preliminar do trabalho de tradução como (re)montagem costuma se manifestar de modo mais patente. Tanto mais numa tradição editorial como a brasileira, em que, para além da predominância da prática de tradução de poesia como poesia (a exemplo da circunscrição de objeto proposta por Haroldo de Campos), a poesia estrangeira traduzida é publicada muito mais raramente no formato de obra completa ou de livro de poemas (assim como organizado

de que essa tradução teria tomado a edição de 1774 como texto de base (Goethe, Johann Wolfgang von. Os sofrimentos do jovem Werther, tradução anônima do século XIX, introdução de Oliver Tolle. São Paulo: Hedra, 2006). 
e publicado pelo próprio poeta) do que no formato de antologias. ${ }^{10}$ Isso é o que também afirma Paulo Henriques Britto em seu artigo "O tradutor como antologista": "o mais frequente é o tradutor selecionar os poemas que ele próprio traduz; ou seja, ele acumula as funções de poeta, tradutor e antologista" (Britto 25). E para o autor, há uma consequência direta desse trabalho de antologista para a cena de recepção da poesia:

\begin{abstract}
[...] os poemas que ele seleciona para traduzir muitas vezes passam a ser encarados pelos leitores de sua tradução não como representando a obra do poeta traduzido, e sim, metonimicamente, como sendo a própria obra. [...] assim, ao selecionar as peças que serão vertidas para seu idioma, o tradutor está também, de certo modo, criando uma obra, e criando um autor, se usarmos o termo 'autor', como se tornou comum fazer nas últimas décadas, para designar não uma pessoa física, e sim um determinado conjunto de textos (Britto 25-26).
\end{abstract}

Ou seja, ao inventar um modo particular de exposição da obra de determinado poeta, o tradutor se torna responsável pela formação (e transformação!) da imagem dessa obra e desse poeta na língua para a qual traduz, razão pela qual Britto sublinha a importância dos critérios utilizados na organização da antologia, vislumbrando duas alternativas mais gerais: a antologia baseada num recorte representativo da obra, com o intuito de evitar que os

\footnotetext{
${ }^{10}$ É interessante observar que se, por um lado, esse quadro acaba formando uma cena de recepção de poesia estrangeira que apenas muito raramente se constrói a partir da circulação de uma porção mais ampla das obras dos autores possibilidade que poderia ser favorecida a partir da tradução mais sistemática de obras completas ou de um conjunto maior de livros de poemas de cada poeta -, por outro lado, a predominância da modalidade da antologia pode ser entendida, também, como sintoma de uma atividade tradutória que, ao menos no Brasil, está predominantemente ligada ao gesto do corte, do recorte e da (re)montagem procedimentos críticos por definição.
} 
efeitos de metonimização da seleção produzam distorções indesejáveis na recepção da obra; ou ainda, sabendo-se que a obra não será traduzida por inteiro, a antologia baseada nos poemas mais bem realizados pelo autor, com o intuito de que a seleção ofereça o que o poeta tem de "melhor" em sua obra (Britto 27). Na sequência de sua reflexão, Britto problematiza essas duas possibilidades, mostrando, muito pertinentemente, não apenas como cada uma dessas alternativas pode produzir imagens muito distintas de um mesmo autor, mas também como é difícil levar a cabo cada uma dessas alternativas no caso de determinados autores.

As duas alternativas elencadas por Britto fazem um recorte da obra estrangeira de maneira mais ampla, mas cabe lembrar que há outros critérios que podem definir o eixo crítico em torno do qual se articula um projeto de antologização e tradução, muitos dos quais capazes de produzir um recorte mais particularizante da obra, como, por exemplo: determinada fase da vida do poeta (poemas de juventude, poemas da maturidade), uma questão temática (poemas eróticos, poemas de outono, poemas marinhos), uma questão de forma poética (sonetos, poemas em prosa), a língua em que os poemas foram escritos originalmente (poemas ingleses, poemas franceses), determinada condição de produção (poemas traduzidos, poemas inacabados), uma questão de recepção (poemas ainda inéditos em português, poemas do espólio) ou, ainda, critérios definidos em função de alguma questão crítica de relevância para a obra. Isso para não falar das antologias que, ao invés de se concentrarem na obra de um único autor, propõem-se a colocar em relação, a partir de alguma perspectiva em comum, um recorte da obra de diferentes poetas.

Augusto de Campos e Haroldo de Campos nos oferecem exemplos paradigmáticos de algumas destas e de várias outras possibilidades de organização de projetos de tradução e antologização de poesia estrangeira. Além da reunião e apresentação crítica dos provençais, dos metafísicos ingleses e simbolistas franceses na obra Verso reverso controverso, publicada por Augusto de Campos em 1978 - obra também mencionada exemplarmente por 
Britto $(2016,34)$-, cabe lembrar, aqui, de obras como: Escrito sobre Jade: poesia clássica chinesa reimaginada por Haroldo de Campos (publicada por Haroldo de Campos originalmente em 1996 e reeditada postumamente, em versão ampliada, em 2009), dedicada à poesia (clássica) chinesa; Linguaviagem, publicada por Augusto de Campos em 1987, dedicada à relação Mallarmé-Valéry e à relação Keats-Yeats; além dos trabalhos de Augusto de Campos dedicados a Cummings, Hopkins, Rimbaud, Rilke, Stramm, entre outros, e dos trabalhos que Haroldo de Campos dedicou, sozinho ou em parcerias, a Dante, Goethe, Maiakovski, Ezra Pound, Mallarmé e, entre outros, à escritura bíblica (traduzida numa perspectiva poética).

É curioso notar, no entanto, que se, por um lado, a prática de tradução poética e o pensamento tradutório desses dois nomes tão importantes da cena da poesia e da tradução vêm sendo estudados e debatidos há várias décadas, por outro lado, ainda são raros os estudos centrados no modo particular de organização de suas antologias, ou seja, interessados nas especificidades dos objetos de invenção que as antologias constituem e na força poética e crítica que engendram. É provável que essa lacuna diga respeito mais a uma falta de atenção à própria constituição crítico-poética das antologias como questão, do que a uma falta de interesse por esse aspecto da obra desses dois autores.

Estabelecer a unidade textual e tradutória do texto de base de uma antologia, mais do que um trabalho de seleção e delimitação (definição de seus elementos constituintes: o que faz parte e o que fica de fora), é também um trabalho de organização do corpus textual selecionado (definição de uma determinada ordem, sequência etc.). Ou seja: além de cortar e recortar a obra do poeta estrangeiro, o tradutor é responsável, também, por (re)montá-la na forma particular de sua antologia. E isso significa dizer que os poemas traduzidos em uma antologia não ganham sentido apenas por si mesmos ou por sua relação com uma origem, mas, também, pela posição que ocupam na antologia como uma forma particular 
de (re)montagem da obra, como forma particular de exposição do corpus poético de determinado autor. ${ }^{11}$

Além disso, como tão bem demonstram os trabalhos de Augusto de Campos e Haroldo de Campos, a antologia não está necessariamente (nem exclusivamente) a serviço da reprodução de uma determinada ordem de valores e valorações estabelecida na cena literária de origem; na condição de (re)montagem, com toda a força que essa noção catalisa - da problematização eisensteiniana da montagem à montagem benjaminiana como princípio -, a antologia pode fazer justamente o contrário: pode pretender abalar certa visão consolidada de determinada obra, reconfigurar seus nexos, produzir novas conexões. Ou ainda, para dizer o mesmo com Didi-Huberman: "A montagem talha as coisas habitualmente reunidas e conecta as coisas habitualmente separadas. Ela cria, portanto, um abalo e um movimento" (Didi-Huberman 6). Nessa cena da tradução de poesia como (re)montagem, o tradutor antologista surge como tradutor-editor, tradutor-montador, tradutor-diretor de um objeto de leitura que solicita (abala, agita) o leitor, mobilizando nele diferentes formas de atenção.

\section{A refazenda brechtiana de André Vallias}

Lançada na primavera de 2019, a obra Bertolt Brecht: poesia, de André Vallias, merece atenção por várias razões. Destaque-se, logo de partida, o grande marco que representa a tradução de 300 poemas do autor alemão - dentre os quais alguns poemetos, como "Nos tempos de escuridão" (Brecht 359), mas também vários poemas mais longos, como, por exemplo, a "Lenda do soldado morto" (Brecht 87-91) ou "Da infanticida Marie Ferrar" (Brecht 143147) -, publicados em edição bilíngue, tornando esta a edição mais abrangente da poesia de Brecht em língua portuguesa; mas não são

11 Cf. Didi-Huberman (2-3), com Benjamin. Agradeço à Viviane Veras pela gentileza da lembrança desse belo ensaio.

Cad. Trad., Florianópolis, v. 41, no 3 p. 33-57, set-dez, 2021. 
apenas os 30 ou 40 poemas a mais do que o total de poemas traduzidos por Paulo César de Souza em sua antologia monolíngue ${ }^{12}$ - publicada originalmente em 1986, com 270 poemas, e reeditada em 2000, com 10 poemas a menos - que fazem da antologia de Vallias uma obra fora da curva. Bertolt Brecht: poesia é também o resultado de um trabalho de seleção e tradução de incontáveis fragmentos de diários e anotações autobiográficas, fotografias, além de 20 textos breves sobre poesia; e todo esse corpus poético-crítico ainda é acompanhado por um ensaio introdutório de fôlego (são mais de 60 páginas) e de um amplo aparato de notas, que literalmente transbordam o espaço da edição em papel - mesmo sem as cerca de 50 páginas da adenda digital, a obra soma vultosas 584 páginas. O reconhecimento público dos méritos do trabalho rendeu à obra (e ao seu tradutor), em 2020, o Prêmio Jabuti de Tradução.

O trabalho de Vallias, no entanto, vai além desses números impressionantes. Na orelha do livro, Augusto de Campos antecipa, com precisão, um traço importante do projeto, a que ele se refere como um "Bertolt Brecht em montagem poética" (grifo meu). E chamando assim a atenção para esse aspecto da montagem, tão frequentemente negligenciado - e não apenas pela crítica - na tradição de tradução e antologização de poesia estrangeira no Brasil, acrescenta: "O livro não é só uma coleção muito representativa de sua poesia [de Brecht], mas incorpora dados biográficos, fragmentos de diários e anotações, vários dos quais documentos inéditos entre nós, inter-relacionados com a poesia e mediados por fotos e imagem em articulada montagem conceitual" (Campos, A, grifo meu). Trata-se aqui, portanto, de uma atenção especial ao modo de fazer

${ }^{12} C f$. Brecht, Bertolt. Poemas 1913-1956. Seleção e tradução de Paulo César de Souza. São Paulo: Editora 34, 2000. Na década de 60, Geir Campos publicou uma antologia, monolíngue, com 143 poemas ( $c f$. Brecht, Bertolt. Poemas e Canções. Rio de Janeiro: Civilização Brasileira, 1966). A propósito das traduções de Brecht para o português, vide o item 7 da introdução de André Vallias (Vallias apud Brecht 13-19, paginação da adenda digital, disponível em: http://andrevallias. com/brecht). 
o livro, ou ainda, ao livro como o resultado de um trabalho poético, crítico e tradutório que é também da ordem da (re)montagem. ${ }^{13}$

A começar por seu "Laboratório Versatilidade" - como o tradutor chama (com Benjamin) sua introdução -, concebida literalmente como um "texto-montagem" (Vallias apud Brecht 547), que faz da forma da exposição, da mostra, seu modo de apresentação, dando consequência ao princípio benjaminiano da montagem literária, como definido pelo pensador alemão em sua obra das Passagens. ${ }^{14}$ Estruturalmente, a antologia se constrói em seis grandes capítulos, que apresentam as oito estações de uma longa viagem no tempo e no espaço, ao redor do mundo, da vida e da obra de Brecht, criando assim um modo produtivo e original de conferir novos sentidos a um padrão cronológico de organização, que, em algumas antologias, impõe-se apenas como uma baliza convencional - e, não raro, artificial. Cada estação, por sua vez, é (re)montada como um encadeamento de imagens fotográficas, excertos dos diários e de anotações autobiográficas, que, na força de seu conjunto, traçam os contornos em que se inscreve cada arranjo de poemas.

Mas, em Bertolt Brecht: poesia, tradução é (re)montagem também no sentido da própria escrita tradutória como um fazer poético, ou seja, no sentido de uma atividade que tem em vista remontar a máquina viva da criação - para lembrar aqui da formulação de Haroldo de Campos. Portanto, trata-se de fazer poesia em língua portuguesa, no Brasil de hoje, e este é o modo privilegiado pelo

${ }^{13}$ Outros projetos de André Vallias podem ser lidos produtivamente na perspectiva da tradução poética como (re)montagem, a exemplo de seu Heine, hein? antologia de poemas de Heinrich Heine, em que o encadeamento de séries de poemas e textos em prosa (do próprio poeta e de seus contemporâneos) já surge como procedimento estruturante na montagem da antologia (Heine, Heinrich. Heine, hein? Poeta dos contrários, tradução e introdução de André Vallias. São Paulo: Perspectiva, 2011) - e de seu poema digital Trakltakt - investigação líricofilológica acerca da poesia de Georg Trakl no espaço-tempo de sua traduzibilidade (Vallias, André. Trakltakt, 2004 Disponível em: http://www.andrevallias.com/ trakltakt/).

${ }^{14}$ Como afirma o pensador: "Método deste trabalho: montagem literária. Não tenho nada a dizer. Somente a mostrar” (Benjamin 502). 
tradutor para fazer esses poemas remontarem aos seus originais em alemão. Tendo isso por horizonte, André Vallias consegue fazer com que seus poemas se sintam tão à vontade em nosso idioma quanto ele parece se sentir à vontade com a poesia de Brecht. Isso se manifesta, por exemplo, na autonomia com que o tradutor dispõe de seu repertório rímico, que inclui achados instigantes como a rima de "sacerdote" com "scotch", de "diz que" com "uísque" ou de "inconteste" com "Brecht". Ou em seu uso atento e perspicaz, quase como um dispositivo rímico, da chamada gebrochener Reim (rima quebrada) - produzida a partir de uma espécie de enjambement morfológico -, um recurso poético em geral mais raro, mas de que Brecht se vale com frequência. Ou, ainda, na precisão com que o tradutor reinscreve os poemas num tempo que é também o nosso tempo, na contemporaneidade da nossa leitura: por vezes, de modo mais pontual, como no caso da figura do dinheiro por baixo da camisa, que, no "Cântico de Mahagonny n. 1", surge como uma cueca forrada de cédulas (Brecht 167); por vezes, como uma reambientação do poema como um todo, como acontece na "Gründungssong der National Deposit Bank".

Na tradução de Vallias, esse poema ganha corpo em português como o "Funk de fundação do Banco Nacional de Depósitos" (Brecht 237). O tradutor justifica o procedimento em nota, nos termos de uma licença poética para poder se valer de um termo de língua inglesa que funcionasse, em português brasileiro, como o termo song do poema em alemão (Vallias apud Brecht 555). Acontece que, especialmente numa edição bilíngue, a opção pelo funk (gênero musical surgido na década de 1960) como tradução do termo song usado num poema de Brecht, datado de 1930, chama a atenção até mesmo de um leitor para quem o restante do texto em alemão fosse predominantemente opaco. Trata-se, aqui, de uma daquelas ocasiões em que o movimento do tradutor parece mobilizar uma força grande o suficiente para impor sua condição de evidência como gesto tradutório. E a força dessa evidência nos mobiliza como leitores, pois alguma coisa acontece nessa tradução. A opção pelo funk não é um esforço paliativo de remontar 
ao objeto indireto do poema original, não é uma tentativa de dizer precariamente (porque em tradução) alguma coisa do que a Gründungssong, de Brecht, sempre será capaz de dizer tão plenamente (porque no original). Na economia tradutória desse poema, o tradutor estabelece novo valor de conversão entre song e funk: é em sua (re)montagem como funk, instrumento de manifestação cultural de uma parcela oprimida da sociedade, que o poema ironiza os instrumentos capitalistas de "viabilização" do projeto de fundação de um banco; é em sua (re)montagem como funk, gênero marginal em sua origem (seja a americana ou a brasileira), que o poema coloca, lado a lado, armas e ações, ladrões e banqueiros; enfim, é em sua (re)montagem como funk que esse poema acusa hoje, como questão sombriamente atual, contemporânea, a mesma violência hipócrita que a Gründungssong acusava em 1930. E é por isso que um poema como este, entre tantos outros dessa antologia, merece a atenção mais detida de um estudo aprofundado.

Em síntese, mais do que selecionar, traduzir, anotar e introduzir esses textos todos, a obra construída por Vallias é um grande exemplo do que uma antologia de poesia traduzida pode fazer quando se mostra capaz de desdobrar crítica e criativamente as diversas facetas de uma compreensão do traduzir como um (re)montar. Levando às últimas consequências todas as dimensões crítico-criativas da prática de tradução de poesia (como tradutor, poeta, antologista e crítico), somadas ainda à concepção e assinatura da capa ${ }^{15}$ e do projeto gráfico, o trabalho de Vallias corta e recorta o corpus da obra brechtiana para montar um livro (quiçá um livro de artista?) que é também um objeto quase fílmico. Na singularidade de seu arranjo poético-crítico e estético-discursivo, muito além de simplesmente dispor poemas de Brecht diante de nossos olhos, numa ordem determinada apenas por algum princípio mais genérico e convencio-

${ }^{15}$ Para citar apenas um exemplo do grau de atenção aos detalhes: o papelão cinza que compõe a imagem de fundo das orelhas do livro parece remeter às "capas de papelão cinza" dos cadernos publicados por Brecht nos anos 30 (Brecht, Bertolt Brecht: Poesia, p.25). 
nal, o tradutor organiza esse corpus como se escrevesse o roteiro de um road movie ou, ainda, como se assumisse a direção geral de uma grande montagem brechtiana, dando a marcação e pautando a entrada em cena de cada poema.

Cabe lembrar ainda que esse trabalho se inscreve numa longa história de recepção de Brecht no Brasil, construída grandemente a partir da repercussão de seu trabalho inovador no teatro, a despeito das várias gerações de tradutores que também se ocuparam de sua obra poética. O poeta Bertolt Brecht, portanto, está longe de ser um desconhecido para o leitor brasileiro. Nesse sentido, o trabalho de Vallias se configura como uma forma de (re)montagem também do ponto de vista dessa condição particular de recepção de sua obra, ou seja, na medida em que seu trabalho pode ser entendido como uma retradução de Brecht: seja no sentido mais estrito, porque Vallias traduz de novo alguns poemas já previamente traduzidos, seja num sentido mais amplo, porque, mesmo traduzindo o que até então era inédito em português, o tradutor reinscreve esse material em uma longa tradição de construção da imagem de Brecht e de sua obra em nossa lingua. A (re)montagem se impõe, assim, como signo e sina da cena de tradução e recepção: como um fazer que é sempre um fazer de novo da obra em tradução, um fazer re-tradutório, um refazer tradutório, enfim, uma refazenda - para fazer reverberar, aqui, o título tanto do LP lançado por Gilberto Gil em 1975 quanto também de uma de suas 11 canções.

Ao longo das últimas décadas, gerações de poetas e tradutores aprenderam a traduzir com Augusto de Campos e Haroldo de Campos, mas ainda são raros os projetos de tradução e antologização pensados e realizados de modo crítico e inovador, como esses dois poetas e tradutores paulistas nos ensinaram ser possível fazer - e como André Vallias faz de modo exemplar. Nas águas nunca as mesmas (mas por revide) dessa refazenda brechtiana, resistindo às expectativas mais convencionais das transitividades tradutórias, Bertolt Brecht: poesia remonta suas fontes, porque a Brecht não se diz voltar... um rio se vai. 


\section{Referências}

Benjamin, Walter. Passagens. Organização e posfácio de Willi Bolle e Olgária Chain Féres Matos; Tradução de Irene Aron e Cleonice Paes Barreto Mourão. Belo Horizonte: Editora UFMG; São Paulo: Imprensa Oficial do Estado de São Paulo, 2006.

Brecht, Bertolt. Poemas e Canções. Rio de Janeiro: Civilização Brasileira, 1966.

Brecht, Bertolt. Poemas 1913-1956. Seleção e tradução de Paulo César de Souza. São Paulo: Editora 34, 2000.

Brecht, Bertolt. Bertolt Brecht: Poesia. Introdução e tradução de André Vallias. São Paulo: Perspectiva, 2019. Adenda digital disponível em http://andrevallias. com/brecht.

Britto, Paulo Henriques. "O tradutor como antologista". Literatura Traduzida: antologias, coletâneas e coleções. Torres, Marie-Hélène; Freitas, Luana Ferreira de; Costa, Walter Carlos (org.). Fortaleza: Substânsia, 2016, pp.23-35.

Berman, Antoine. Pour une critique des traductions: John Donne. Paris: Gallimard, 1995.

Campos, Augusto de; Campos, Haroldo de; Pignatari, Décio. Teoria da Poesia Concreta: textos críticos e manifestos 1950-1960. São Paulo: Livraria Duas Cidades, 1975, pp.156-158.

Campos, Augusto de. "Bertolt Brecht em montagem poética", texto de orelha. Brecht, Bertolt. Bertolt Brecht: Poesia. Introdução e tradução de André Vallias. São Paulo: Perspectiva, 2019.

Campos, Haroldo de. "Da tradução como criação e como crítica". Metalinguagem \& outras metas: ensaios de teoria e crítica literária, Campos, Haroldo de (Ed.). São Paulo: Perspectiva, 1992, pp.31-48. 
Campos, Haroldo de. "Da razão antropofágica: diálogo e diferença na cultura brasileira". Metalinguagem \& outras metas: ensaios de teoria e crítica literária, Campos, Haroldo de (Ed.). São Paulo: Perspectiva, 1992, pp.231-255.

Campos, Haroldo de. Deus e o Diabo no Fausto de Goethe: marginalia fáustica (leitura do poema acompanhada da transcriação em português das duas cenas finais da segunda parte). São Paulo: Perspectiva, 2005.

Campos, Haroldo de. Haroldo de Campos - Transcriação. Organização de Marcelo Tápia e Thelma Médici Nóbrega. São Paulo: Perspectiva, 2013.

Cardozo, Mauricio Mendonça. "Tradução e o trabalho de relação: notas para uma poiética da tradução". O trabalho da tradução. Pietroluongo, Márcia Atálla (org.). Rio de Janeiro: Ed. ContraCapa, 2009, pp.181-188.

Cardozo, Mauricio Mendonça. Tradução como transformação: liminaridade, incondicionalidade e a crítica da relação tradutória. Revista Letras, 85 (2012):181201. DOI: http://dx.doi.org/10.5380/rel.v85i1.27796. Disponível em: https:// revistas.ufpr.br/letras/article/view/27796/19491 Acessado em 10.12.2020.

Cardozo, Mauricio Mendonça. Literatura e tradução: descontinuidades na ficção do outro. Revista Brasileira de Literatura Comparada, 24 (2014, publicada em 2015): 08-125. Disponível em: https://revista.abralic.org.br/index.php/revista/ article/view/326/330 Acessado em 10.12.2020.

Cardozo, Mauricio Mendonça. "Tradução e o (ter) lugar da relação". Pensando a Política com Derrida: responsabilidade, tradução, porvir. Lopes, Alice Casimiro; Siscar, Marcos (org.). São Paulo: Cortez, 2018, pp.285-321.

Cardozo, Mauricio Mendonça. "Mein werter Herr Werther: à guisa de nota liminar". Os sofrimentos do jovem Werther, Goethe, Johann Wolfgang von (Ed.); tradução e notas Mauricio Mendonça Cardozo; introdução Michael Hulse. São Paulo: Penguin-Companhia das Letras, 2021, p.29-43.

Didi-Huberman, Georges. Remontar, remontagem (do tempo). Tradução de Milene Migliano. Belo Horizonte: Chão da Feira, 2016. Acessado em 20.01.2020. Disponível em: https://chaodafeira.com/wp-content/uploads/2016/07/cad_47.pdf 
Goethe, Johann Wolfgang von. Die Leiden des jungen Werthers - Die Wahlverwandtschaften - Kleine Prosa - Epen. Organização de Waltraud Wiethölter, com colaboração de Christoph Brecht. Frankfurt am Main: Deutscher Klassiker Verlag (DKV), 2006.

Heine, Heinrich. Heine, hein? Poeta dos contrários. Tradução e introdução de André Vallias. São Paulo: Perspectiva, 2011

Perrone-Moisés, Leyla. Altas literaturas: escolha e valor na obra crítica de escritores modernos. São Paulo: Companhia das Letras, 1998.

Siscar, Marcos. Não se diz. Rio de Janeiro: 7 Letras, 1999.

Siscar, Marcos. Metade da Arte. São Paulo; Rio de Janeiro: Cosac \& Naify; 7 Letras, 2003.

Tarallo, Fernando. "Aspectos Sociolinguísticos da Tradução”. Tradução: teoria e prática. Coulthard, M; Caldas-Coulthard, C. R. (org.). Florianópolis: Editora da UFSC, 1991, pp. 33-46.

Recebido em: 06/04/2021

Aceito em: 15/07/2021

Publicado em setembro de 2021

Mauricio Mendonça Cardozo. E-mail: maumeluco@gmail.com. ORCID: https:// orcid.org/0000-0001-9270-6892. 